\title{
Comunicar con TIC: desafíos y posibilidades
}

\section{Communicate with ICT: challenges and possibilities}

\author{
María Esperanza Ramírez maryarifran@gmail.com \\ https://orcid.org/0000-0003-4062-8890 \\ Facultad de Periodismo y Comunicación Social; Universidad Nacional de La Plata (Argentina)
}

\section{Resumen}

Este artículo reseña el Ebook La aventura de innovar con TIC II: aportes conceptuales, experiencias y propuestas, edición de la Facultad de Periodismo y Comunicación Social, Universidad Nacional de La Plata, en el que se reflexiona sobre el lugar que en la actualidad tienen las tecnologías en los distintas salidas laborales del comunicador social: docencia, periodismo y planificación. Con prólogo de Omar Rincón, en una primera parte se presenta una serie de reflexiones sobre temáticas contextuales generales. El resto del volumen incluye algunos trabajos finales de la cohorte 2016 del Seminario Estrategias de trabajo colaborativo con redes sociales virtuales y otros asistentes online que se dicta en la FPyCS-UNLP, en los 
que se vislumbran las potencialidades y los desafíos que el nuevo contexto digital y de redes les presenta a los comunicadores del siglo XXI.

Palabras clave: TIC; comunicación; docencia; periodismo; planificación.

\section{Abstract}

This article reviews the Ebook The adventure of innovating with ICT II: conceptual contributions, experiences and proposals, edited by Faculty of Journalism and Social Communication, Universidad Nacional de La Plata. The book reflects the place that technologies have nowadays in the different labor outlets of the social communicator: teaching, journalism and planning. With a foreword writen by Omar Rincón, the first part includes a series of reflections on general contextual issues. The rest of the volume includes some final works of the 2016 cohort of the Seminar Estrategias de trabajo colaborativo con redes sociales virtuales y otros asistentes online given in the FPyCS-UNLP. Each article introduces the potentialities and challenges of the new digital and network context for the communicators of the 21 st century.

Keywords: ICT; communication; teaching; journalism; planning.

En la actualidad, las TIC (Tecnologías de la Información y la Comunicación), están más presentes que nunca en nuestras vidas cotidianas, irrumpieron en la cultura del siglo XX y se han tornado inherentes a las prácticas de niños, jóvenes y adultos, quienes las utilizan para comunicarse, entretenerse e informarse.

La realidad es que muchas veces resulta difícil y complejo incorporarlas de forma efectiva y productiva, ya sea por razones tecnológicas, falta de herramientas o conectividad, materiales y lo más importante: una capacitación adecuada. La Aventura de Innovar con TIC II: Aportes conceptuales, experiencias y propuestas, es un Ebook que refleja el compromiso de un trabajo conjunto entre docentes, adscriptas y estudiantes del Seminario Taller Estrategias de trabajo colaborativo para el aula con redes sociales virtuales y otros asistentes online, que se dictó por primera vez en 2014, como materia optativa y cuatrimestral para alumnos de la carrera del Profesorado en Comunicación Social. Dos años más tarde, se amplió su matrícula para los cursantes de las Licenciaturas con orientación en Periodismo y Planificación, quienes también 
pudieron ser parte de esta experiencia, en la Facultad de Periodismo y Comunicación Social de la Universidad Nacional de La Plata, Argentina.

Este nuevo Ebook profundiza la línea de reflexiones conceptuales y sistematizaciones de experiencias de enseñanza abordadas en el volumen I. Los artículos que integran la publicación corresponden a dos partes bien diferenciadas: en la primera, apartados ligados a interrogantes, categorías y mutaciones que genera el nuevo escenario digital. En la segunda, se recupera para su visibilización y ejemplificación distintas actividades teóricas o prácticas desarrolladas por los estudiantes del Seminario, con la finalidad de ilustrar cómo es posible incorporar las TIC de forma significativa para el trabajo del comunicador, interactuando con sus pares, incluyendo los entornos digitales de forma crítica y produciendo recursos digitales de manera sencilla.

Esta segunda entrega está prologada por Omar Rincón, referente colombiano del campo de la Comunicación Social, quien con su mirada atenta y profunda recorre diferentes ejes sobre la utilización de TIC en la actualidad, ya se trate de herramientas que utilizan profesores, como periodistas y planificadores. En sus palabras, invita al lector a reflexionar sobre la hegemonía de lo escritural, y cómo las pantallas permiten la expresión en otros formatos orales como es el caso de WhatsApp.

En la publicación, como se ha mencionado el lector encontrará reflexiones sobre los cambios que traen las nuevas tecnologías en cuanto a políticas educativas y comunicacionales, circulación del conocimiento y formas de enseñar. El apartado que corresponde a la autoría de María Victoria Martin aborda los efectos de los medios en las relaciones de poder institucionalizadas en nuestras sociedades. A continuación, se encuentra el capítulo que escriben conjuntamente Sebastián Novomisky y Gladys Manccini, docentes y miembros de la gestión actual de la FPyCS de la UNLP, en el que describen las políticas públicas de acceso a las tecnologías que en los últimos años se implementaron en Latinoamérica, con el fin de acortar las brechas digitales. En esa línea, proponen claves para analizar la era digital y su articulación con los procesos pedagógicos. Luego, Pamela Vestfrid, se centra en el rol del educador, en un contexto de convergencia digital que impone otras formas de vinculación con los estudiantes, entendiéndolos como prosumidores gracias a las modificaciones en las formas de registro, almacenamiento y circulación de la información y los bienes culturales. Finalmente, se encuentra el capítulo elaborado por Gisela Assinnato, quien se refiere a cómo realizar búsquedas online y, ligado a ello, qué son y cómo utilizar repositorios académicos, con el propósito de recuperar fuentes confiables de la red.

La segunda parte del Ebook, se completa con la presentación de diversas producciones de los estudiantes de la cohorte 2016 del seminario. Allí, se visibilizan experiencias concretas sobre la 
utilización de las TIC en distintos ámbitos profesionales, generando un diálogo permanente entre la teoría y la práctica, tales como la implementación de múltiples asistentes digitales, en muchos de los cuales predomina lo visual por sobre lo escritural (nubes de etiquetas, historietas, mapas conceptuales y pósters) y otras más ligadas a los contenidos conceptuales de la asignatura. Entre ellos, las normativas y legislación que regulan los medios de comunicación en la Argentina y la incorporación de tecnologías en los distintos niveles y modalidades del sistema educativo. Además, analiza y reflexiona sobre los sujetos de esta nueva era digital, que exceden los conceptos de nativos e inmigrantes digitales. Los trabajos colaborativos en educación mediados por TIC como procesos de enseñanza y aprendizaje que superan la mera división de tareas.

Con un lenguaje sencillo y un estilo ágil, se invita al lector a recorrer los distintos apartados. Que sea digital, posibilita su circulación por distintos espacios, revalorizando las producciones de los alumnos, que se han vuelto autores.

Muchos educadores y comunicadores se aventuraron a cruzar la barrera del simple ocio al empoderamiento con las TIC, para facilitar sus prácticas. No cabe duda que Internet rompe barreras espaciotemporales, acorta brechas y nos mantiene conectados.

La Aventura de Innovar con TIC II es un material educativo que invita a pensar y reflexionar sobre el uso y la apropiación de las tecnologías no solo en el ámbito educativo, sino también en el campo de la Comunicación Social en sentido general.

Pueden seguir el Ebook a través de Facebook en laaventuradeinnovarcontic y también descargarlo en forma gratuita desde http://bit.ly/32ARSvA

\section{Bibliografía}

Martín, M. V. y Vestfrid, P. (2018). La aventura de innovar con TIC II: aportes conceptuales, experiencias y propuestas. La Plata: Universidad Nacional de La Plata, Facultad de Periodismo y Comunicación Social. Recuperado de http://bit.ly/32ARSvAl 